\title{
Internal Auditor Participation In Systems Development Projects
}

\author{
Meredith Maher, (E-mail: Meredith.Maher@Marquette.edu), Marquette University
}

Michael D. Akers, Ph. D., CIA, CPA, CMA, CFE, (E-mail: Michael.Akers@ Marquette.edu), Marquette University

\begin{abstract}
There are differing viewpoints in the internal auditing literature regarding the role of internal audit in systems development projects. One argument is that internal audit should act as consultants for such projects. A counter argument is that if internal auditors act as consultants, this could impair independence. This study surveyed chief audit executives to determine their perceptions of the role of internal audit in systems development projects as well as the actual involvement of their departments in such projects. The findings show that chief audit executives place more importance on internal audit acting as consultants and less importance on independence in these projects. The results also suggest that internal audit has limited involvement in the different phases of the Systems Development Life Cycle of these projects.
\end{abstract}

\section{Introduction}

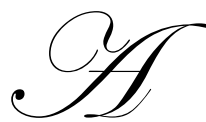

$\mathrm{s}$ the business environment changes and process integration increases, internal auditors continue to be the sought after as experts in controls and process improvement. In the 1980's and 1990's the role of internal audit shifted from the police or watchdogs of an organization to a new consulting role, particularly within information systems arenas. With this increased focus on consulting, the very nature of internal auditor independence is called into question. Drent (2002) determined that there is a significant different between the expectations of audit committees and management on the importance of internal audit independence. Drent found that audit committees place a high level of importance on independent internal auditors, while, executive and line management placed a low level of importance on independence. He noted that management does not appreciate the need for independence; however, audit committees understand its importance and basis in governance. The Institute of Internal Auditors, however, believes that independence is very important as evidenced in the Institute's Professional Practices Framework and Standards.

The purpose of this paper is to examine the role (perceived role and actual involvement) of internal audit in systems development projects. To determine this, chief audit executives were surveyed. The first section of the paper provides an overview of internal audit's independence requirements as defined by the Institute of Internal Auditors (IIA) and the Information Systems Audit and Control Association. The second and third sections describe the study and results. The last section provides concluding comments.

\section{Independence Requirements in Systems Development Projects}

The Institute of Internal Auditors' Practice Standards state that "internal auditors should be independent of the activities they audit" and that "internal auditors should be objective in performing audits." Recently, the IIA adopted a Professional Practices Framework that defines internal auditing as an "independent, objective assurance and consulting activity" (Colbert, 2002). Colbert adds, "The concept of independence applies to both the internal audit activity and individual internal auditors." Internal audit as a function would be independent if it is reporting to the appropriate function within the organization. Individual internal auditors should have an impartial, unbiased attitude with respect to each audit (Colbert, 2002). The Information Systems Audit and Control Association (ISACA)

Readers with comments or questions are encouraged to contact the authors via email. 
Code of Professional Ethics state that auditors should "perform their duties in an independent and objective manner and avoid activities that impair, or may appear to impair, the independence or objectivity."

\section{Study}

\subsection{Survey Instrument}

A questionnaire was developed that solicited the Chief Audit Executive's perception regarding the role of Internal Audit in systems development projects as well as the actual involvement of their internal audit departments in such projects. In examining both issues (perception and actual involvement), the questionnaire was designed to obtain input regarding each phase of Systems Development Life Cycle (SDLC): planning, design, development, testing, implementation, and maintenance. A copy of the survey appears in Appendix A.

The first part of the questionnaire (questions 1 to 4 ) relates to demographic information of the respondent such as the type of corporation (Fortune 500), years of work experience, professional certifications, and number of systems development projects that his/her department had been involved with over the last three years. The perceptual questions (questions 5 to 13) related to internal audit independence throughout the various phases of the SDLC. These questions focused on internal audit's role as an auditor and as a consultant. Actual involvement questions (questions 14 to 29) examined the type of involvement by internal auditors in systems development projects. These questions specifically focused the level of participation throughout each phase of the SDLC.

\subsection{Sample}

This survey was distributed to approximately 1700 Chief Audit Executives via the IIA Research Foundation's GAIN web survey system. The GAIN web survey system is a collection of audit executives who have agreed to participate in the benchmarking studies that are sponsored by the Institute of Internal Auditors.

\section{Results}

Three hundred Chief Audit Executives responded to the survey resulting in an 18\% response rate. The discussion of the results has been divided into three sections: demographic data, chief audit executives' perception of the role of internal audit in systems development projects and actual involvement of their departments (by phase of the SDLC and by task). A partial list of respondents is presented in Appendix B.

\subsection{Demographic Data}

Of the 300 survey respondents, $23 \%$ were the chief audit executive at Fortune 500 corporations. The Fortune 500 audit executives had approximately 13 years of experience, while the non-Fortune 500 audit executives had approximately 14 years of experience. The certifications, which are essentially the same for Fortune 500 and nonFortune 500, of these audit executives are shown in Table 1.

Table 1

\begin{tabular}{|c|c|}
\hline Certification & Total \\
\hline CPA & $75 \%$ \\
\hline CIA & $50 \%$ \\
\hline CFE & $26 \%$ \\
\hline CMA & $22 \%$ \\
\hline CISA & $41 \%$ \\
\hline None & $19 \%$ \\
\hline
\end{tabular}

While approximately $86 \%$ of the respondents had been involved with at least one project during the past three years, the chief audit executives involved in multiple projects were considerably less. Thirty-seven percent had been involved with between two and five such projects.

\subsection{Perception of the Role of Internal Audit}

The survey identified nine specific statements about the independence of internal auditors who are involved in systems development projects.

Tables 2 and 3 indicate the overall level of agreement with each statement. The scores are reported on a five-point scale where one represents strongly agree while five is strongly disagree. 
Table 2 - General Perception

\begin{tabular}{|c|c|}
\hline Question & Rating \\
\hline $\begin{array}{l}\text { 1. Internal audit's involvement in systems development projects should be limited to only performing audits after } \\
\text { completion of the project. }\end{array}$ & 4.6 \\
\hline 2. For systems development projects, independence is not a critical objective for internal auditors. & 3.4 \\
\hline 3. Internal auditors should act as consultants in a systems development project. & 2.1 \\
\hline
\end{tabular}

The findings show that chief audit executives believe that internal auditors should have some type of involvement throughout systems development projects. The results also indicate that the respondents place slightly more emphasis on acting as consultants than remaining independent. There is only limited support for independence as a key objective, which is inconsistent with the IIA standards on independence. The results of this study are consistent with the Institute's new standards regarding the internal auditor's role as a consultant. Internal audit executives believe that internal auditors should act as consultants on systems development projects. In addition, survey respondents commented that they "have been revising [internal audit's] role" and "internal audits role in systems development is to act as a 'consultant' to provide information on controls." In December 2001, Norman Marks concurred with these comments by stating that challenging auditors to act as consultants, there is an opportunity to make a real difference in an organization (Marks, 2001).

Table 3 - Chief Audit Executives' Perceptions by Specific SDLC phase

\begin{tabular}{|l|cl|c|}
\hline SDLC Classification & \multicolumn{2}{|c|}{ Question } & Rating \\
\hline Planning Phase & 4. & $\begin{array}{l}\text { Internal auditors should be involved in the planning of systems development } \\
\text { projects. }\end{array}$ & 2.6 \\
\hline Design Phase & 5. & Internal auditors should be involved in the designing the system to be implemented. & 3.2 \\
\hline Development Phase & 6. & $\begin{array}{l}\text { Internal auditors should be involved in writing the code for system to be } \\
\text { implemented. }\end{array}$ & 4.7 \\
\hline Testing Phase & 7. & Internal auditors should be involved in testing the accuracy of the systems. & 2.1 \\
\hline Implementation Phase & 8. & Internal auditors should be involved in implementation of the system. & 3.5 \\
\hline Maintenance Phase & 9. & Internal auditors should be involved with the ongoing maintenance of the system. & 4.3 \\
\hline
\end{tabular}

While internal audit executives are essentially indifferent regarding internal involvement in the design and implementation phases, there is moderate support that internal audit should be involved in the planning phase, and they agree that testing the system to ensure accuracy is important. Chief audit executives don't believe their departments should be involved with the development or maintenance of systems.

\subsection{Actual Involvement in Systems Development Projects}

If their internal audit department participated in systems development projects, then the chief audit executives indicated the level of participation within each phase. Table 4 shows the relative involvement within each of the six phases. The scores are reported on a five-point scale where one is extensive involvement and five is no involvement.

Table 4

\begin{tabular}{|l|l|}
\hline SDLC Phase & Actual Involvement \\
\hline Planning & 3.2 (moderate to little) \\
\hline Design & 3.2 (moderate to little) \\
\hline Development & 3.4 (moderate to little) \\
\hline Testing & 2.7 (considerable to moderate) \\
\hline Implementation & 3.3 (moderate to little) \\
\hline Maintenance & 4.3 (little to none) \\
\hline
\end{tabular}

Internal auditors are spending most of their time auditing the testing phase of the systems development project, followed by the planning and design phases, implementation phase, and development phase. There is little audit work that is focused on the on-going maintenance of the systems. This is consistent with the perceptions of chief audit executives except for the development phase, where the chief audit executive believe their departments should have very limited involvement. The findings suggest that actual involvement is higher. 
The survey identified fourteen phase specific tasks that internal auditors may perform while involved in systems development projects. Tables 5 through 10 indicate the overall level of participation with each activity. The five-point scale was based on always as 1 and never as 5 .

\subsection{Planning}

As noted in Table 5, internal auditors are not typically responsible for specific tasks on the systems development project and do not typically manage the project. These results support the IIA standards that internal audit should be independent. During the planning phase, internal auditors typically attend systems development project meetings and sometimes have representation on the project steering committee.

Table 5-Planning

\begin{tabular}{|ll|c|}
\hline Question & Rating \\
\hline $1 . \quad$ Internal auditors attend systems development project meetings. & 2.8 \\
\hline 2. & Internal audit is responsible for specific tasks of the systems development project plan. & 4.1 \\
\hline 3. Internal audit manages the systems development project. & 4.9 \\
\hline 4. & $\begin{array}{l}\text { Internal audit is represented on the project steering committee that decides the strategic future of } \\
\text { the project. }\end{array}$ & 3.3 \\
\hline
\end{tabular}

\subsection{Design}

In the design phase of the project, internal auditors sometimes attend systems design meetings; however, the project team typically validates audit's recommendations. During this phase, audit does not typically make estimates or assignments of resources to the project.

Table 6-Design

\begin{tabular}{|l|c|}
\hline Question & Rating \\
\hline $5 . \quad$ Internal audit participates in systems design meetings. & 3.4 \\
\hline $6 . \quad$ The project team validates audit's recommendations before the changes are implemented. & 2.7 \\
\hline $7 . \quad$ Internal audit makes estimates and assignments of the needed resources to complete the project. & 4.5 \\
\hline
\end{tabular}

\subsection{Development}

Internal audit does not write or review code developed within the project; however, it sometimes makes assessments of projects risks.

Table 7-Development

\begin{tabular}{|llc|}
\hline Question & Rating \\
\hline $8 . \quad$ Internal audit manages the assessment of project risks. & 3.6 \\
\hline $9 . \quad$ Internal audit writes and reviews the code developed in the project. & 4.9 \\
\hline
\end{tabular}

\subsection{Testing}

In the testing phase, internal audit typically verifies the results of the systems testing or participates in the testing of the new system.

Table 8-Testing

\begin{tabular}{|llc|}
\hline Question & Rating \\
\hline $10 . \quad$ Internal audit participates in the testing of the new system. & 3.2 \\
\hline $11 . \quad$ Internal audit verifies the results of the systems testing. & 2.9 \\
\hline
\end{tabular}




\subsection{Implementation}

Internal audit rarely creates systems documentation for a systems development project. Internal auditor may be present at systems implementation to monitor errors that occur.

Table 9-Implementation

\begin{tabular}{|ll|c|}
\hline Question & Rating \\
\hline $12 . \quad$ Internal audit creates systems documentation. & 4.7 \\
\hline $13 . \quad$ Internal audit is present at systems implementation to monitor if there are systems errors. & 3.5 \\
\hline
\end{tabular}

\subsection{Maintenance}

Internal audit typically performs a formal post-implementation audit of the new system.

Table 10-Maintenance

\begin{tabular}{|l|c|}
\hline Question & Rating \\
\hline $14 . \quad$ Internal audit conducts a formal post-implementation audit of the system & 2.7 \\
\hline
\end{tabular}

The results in Tables 5 through 10 are essentially the same for the Fortune 500 and non-Fortune 500 audit groups, with one exception. Internal auditors at Fortune 500 companies are typically not involved with the project steering committee while the non-Fortune 500 audit departments are moderately involved. This could be due to Fortune 500 companies having larger information technology departments with more technical expertise, specialized information technology audit departments, or more systems development projects with fewer staff.

\section{Conclusion}

The results of the study show that the chief audit executives do not perceive independence as a critical objective for systems development audits, while they do believe that internal auditor should act as consultants. Such findings are consistent with the Institute of Internal Auditor's standards regarding consulting services but are inconsistent with the independence standards. Except for testing the accuracy of the systems, the respondents' perceptions of the of the role of internal audit is either moderate or indifferent regarding the planning, design, development, and implementation phases of systems development projects. Chief audit executives clearly believe that internal audit should not be involved with the maintenance phase. The findings show that actual involvement in systems development projects parallel the perception findings with one exception. While the respondents don't believe internal audit should be involved in the development phase of a systems development project, the findings suggest that internal audit departments are actually involved (moderate to little) in such projects.

\section{Suggestions for Future Research}

Future research should examine how the CEO and the Board of Directors influence the role of the internal audit function in systems development projects. This is particularly important in light of the Sarbanes-Oxley Act as well as other recent changes, for example those enacted by the New York Stock Exchange, that impact the role of Boards and audit committees.

\section{References}

1. Colbert, J. (2002, May). New and Expanded Internal Audit Standards. The CPA Journal, 35-38.

2. Drent, D. (2002, February). The Quest for Increased Relevance. The Internal Auditor, 49-55.

3. Marks, N. (2001, December). The New Age of Internal Auditing. The Internal Auditor, 44-49.

4. Ridley, J. and Yates, E. (2001, December). Worth Repeating. The Internal Auditor, 37-43. 


\section{Authors Biographies}

Meredith Maher is has a Masters in Accounting from Marquette University. She was the Second Vice President of the Milwaukee Chapter of the IIA in 2001-2002.

Michael Akers is an Associate Professor and The Charles T. Horngren Professor of Accounting at Marquette University. He is currently on the Board of Governors of the Milwaukee Chapter of the IIA.

\section{Appendix A-Chief Audit Executive Survey \\ Internal Audit Survey \\ The Role of Internal Audit in Systems Development Projects}

1. Do you work for a Fortune 500 company? Yes No

2. How many years of work experience do you have in the internal auditing field?

3. Which of the following certifications do you have? _ CPA, _ CIA, _ CFE, _ CMA, _ CISA

4. Approximately how many systems development projects has your department been involved with over the last 3 years? _ 0 to $1, \ldots 2$ to $5, \ldots$ Over 5

Please complete each question by responding from Strongly agree (1) to Strongly disagree (5) by circling the corresponding number.

5. Internal audit's involvement in systems development

Strongly

agree

projects should be limited to only performing audits after completion of the project.

6. For systems development projects, independence is not a critical objective for internal auditors.

7. Internal auditors should act as consultants in a systems development project.

8. Internal auditors should be involved in the planning of systems development projects.

9. Internal auditors should be involved in the designing the system to be implemented.

10. Internal auditors should be involved in writing the code for system to be implemented.

11. Internal auditors should be involved in testing the accuracy of the systems.

12. Internal auditors should be involved in implementation of the system.

1

Strongly disagree

2 3

4 5 5

2

3

4 
13. Internal auditors should be involved with the ongoing maintenance of the system.

$\begin{array}{lllll}1 & 2 & 3 & 4 & 5\end{array}$

14. If your internal audit department participates in systems development projects, indicate the degree of participation:

in the planning phase?

_ Extensive, _ Considerable, _ Moderate, _ Little, _ None

in the design phase?

_- Extensive, _ Considerable, _ Moderate, _ Little, _ None

in the development phase? - Extensive, _ Considerable, _ Moderate, _ Little, - None

in the testing phase? $\quad$ - Extensive, _ Considerable, _ Moderate, _ Little, - None

in the implementation phase? - Extensive, _ Considerable, _ Moderate, _ Little, - None

in the maintenance phase? _ Extensive, _ Considerable, _ Moderate, _ Little, _ None

15. Indicate the degree to which your company

develops their own internal software?

purchases and installs packaged software?

or modifies purchased software?
_ Always, _ Mostly, _ Occasionally, __ Never __ Always, _ Mostly, __ Occasionally, __ Never __ Always, _ Mostly, _ Occasionally, __ Never

Please indicate the extent to which your internal audit department participated in the following activities.

16. Internal auditors attend systems development Always project meetings.

17. Internal audit is responsible for specific tasks of the systems development project plan.

18. Internal audit manages the systems development project.

19. Internal audit is represented on the project steering committee that decides the strategic future of the project.

20. Internal audit participates in systems design meetings.

21. The project team validates audit's recommendations before the changes are implemented.

22. Internal audit makes estimates and assignments of the needed resources to complete the project.

23. Internal audit manages the assessment of project risks.

24. Internal audit writes and reviews the code developed in the project.

25. Internal audit participates in the testing of the new system.

26. Internal audit verifies the results of the systems

\begin{tabular}{|c|c|c|c|c|}
\hline 1 & 2 & 3 & 4 & 5 \\
\hline 1 & 2 & 3 & 4 & 5 \\
\hline 1 & 2 & 3 & 4 & 5 \\
\hline 1 & 2 & 3 & 4 & 5 \\
\hline 1 & 2 & 3 & 4 & 5 \\
\hline 1 & 2 & 3 & 4 & 5 \\
\hline 1 & 2 & 3 & 4 & 5 \\
\hline 1 & 2 & 3 & 4 & 5 \\
\hline 1 & 2 & 3 & 4 & 5 \\
\hline 1 & 2 & 3 & 4 & 5 \\
\hline 1 & 2 & 3 & 4 & 5 \\
\hline
\end{tabular}


testing.

27. Internal audit creates systems documentation.

$\begin{array}{lllll}1 & 2 & 3 & 4 & 5 \\ 1 & 2 & 3 & 4 & 5 \\ 1 & 2 & 3 & 4 & 5\end{array}$

29. Internal audit conducts a formal postimplementation audit of the system.

If you are interested in receiving a copy of the study's findings, please provide your name and email below. If you would be willing to be contacted for further information, please check here 


\section{Appendix B - Partial List of Survey Respondents}

\begin{tabular}{|l|}
\hline Deutsche Telekom AG \\
\hline Allegheny Technologies Inc \\
\hline American Electric Power \\
\hline Anadarko Petroleum Corpora- \\
tion \\
\hline Archer Daniels Midland Com- \\
pany \\
\hline Ball \\
\hline Best Buy \\
\hline Caterpillar Inc. \\
\hline Chevron Phillips Chemical \\
Company \\
\hline ChoicePoint \\
\hline CIGNA Corporation \\
\hline Comdisco Inc. \\
\hline Corn Products International, Inc. \\
\hline Dana Corporation \\
\hline Dollar General Corporation \\
\hline Dominion \\
\hline FirstEnergy Corp. \\
\hline Freddie Mac \\
\hline Guardian Life \\
\hline Hartford Financial Services \\
Group, Inc. \\
\hline Hewlett Packard Co \\
\hline Hughes Electronics Corporation \\
\hline IKEA \\
\hline Kerr-McGee Corporation \\
\hline Lincoln Financial Group \\
\hline Microsoft \\
\hline Nextel Communications \\
\hline Norfolk Southern \\
\hline O. G. E. Energy Corp. \\
\hline Ontario Power Generation \\
\hline PepsiAmericas, Inc. \\
\hline PG\&E Corporation \\
\hline Phillips Petroleum Company \\
\hline Progress Energy \\
\hline Progressive Insurance \\
\hline RadioShack \\
\hline Ryder System, Inc. \\
\hline Sempra Energy \\
\hline Smurfit-Stone Container Corp. \\
\hline Sprint \\
\hline Staples \\
\hline
\end{tabular}

\begin{tabular}{|l|}
\hline Starwood Hotels \& Resorts \\
Worldwide, Inc. \\
\hline Steelcase Inc \\
\hline TXU \\
\hline United Services Automobile As- \\
sociation \\
\hline Wells Fargo \\
\hline A.G. Edwards \& Sons, Inc. \\
\hline Air Canada \\
\hline Asian Development Bank \\
\hline Brown University \\
\hline Cableuropa,S.A \\
\hline California State University \\
\hline Canadian Pacific Railway \\
\hline Cargill, Inc \\
\hline CenturyTel \\
\hline CGU Group Canada Insurance \\
\hline City University of Hong Kong \\
\hline Cleveland-Cliffs Inc \\
\hline Coles Myer Ltd \\
\hline College of the Mainland \\
\hline Community Bank System, inc. \\
\hline Community College System \\
\hline Corus Group plc \\
\hline Diebold, Incorporated \\
\hline Dow Jones \& Company, Inc. \\
\hline Duquesne Light Company \\
\hline EDB \\
\hline Edith Cowan University \\
\hline Education Department \\
\hline Electricity Supply Board, Ireland \\
\hline Enterprise Rent-a-Car \\
\hline ESCO Corp. \\
\hline Fedders Corporation \\
\hline Federal Reserve Bank of Cleve- \\
land \\
\hline Hallmark Cards \\
\hline Harvard University \\
\hline HM Prison Service \\
\hline Jefferson Regional Medical Cen- \\
ter \\
\hline Johns Hopkins Institution \\
\hline Kansas State University \\
\hline Kent State University \\
\hline Lebanese American University \\
\hline
\end{tabular}

Longview Fibre Company

LSI Logic Corporation

Manitoba Public Insurance Corp

Minerals Technologies Inc.

National Association of Securi-

ties Dealers, Inc.

National Life Insurance Compa-

ny

Natural Resources and Mines

Nestle Purina Pet Care Company

New York University

NSTAR Electric \& Gas

Palabora Mining Company Ltd

Public University

Scottish Legal Aid Board

Seguros Monterrey

Seton Hall University

Six Continents Hotels

South Somerset D.C.

State Farm Insurance

Stirling Cooke North American

Holdings

Texas Tech University System

Texas Woman's University

The Aga Khan University

The Dial Corporation

The University of Montana

Union National Bank

Univ. of Wisconsin-Madison

University of California Santa

Cruz

University of Iowa

University of Nebraska Medical

Center

University of South Africa

University of South Florida

University of Texas at El Paso

University of Wisconsin-Stout

Virginia State University

Virginia Tech

Vought Aircraft

Washington Group International

Washington State Department of

Labor \& Industries

Whole Foods Market

WTB Financial Corporation 


\section{Notes}

